\title{
Tolcapone, a potent aggregation inhibitor for the treatment of familial leptomeningeal amyloidosis
}

Francisca Pinheiro ${ }^{1}$, Nathalia Varejão ${ }^{1}$, Sebastian Esperante $^{2}$, Jaime Santos ${ }^{1}$, Adrián VelázquezCampoy $^{3}$, David Reverter ${ }^{1}$, Irantzu Pallarès ${ }^{1 *}$ and Salvador Ventura ${ }^{1 *}$

1 Institut de Biotecnologia i Biomedicina and Departament de Bioquímica i Biologia Molecular, Universitat Autònoma de Barcelona, Bellaterra, Barcelona 08193, Spain.

${ }^{2}$ INFANT Foundation, CONICET, Gavilan 94, CABA, Argentina.

${ }^{3}$ Department of Biochemistry and Molecular \& Cellular Biology, and Institute for Biocomputation and Physics of Complex Systems (BIFI), Joint Units IQFR-CSIC-BIFI and GBsC-CSIC-BIFI, Universidad de Zaragoza, Zaragoza (Spain); Aragon Institute for Health Research, Zaragoza (Spain); Biomedical Research Network Center in Hepatic and Digestive Diseases (CIBERehd), Madrid (Spain); ARAID Foundation, Gobierno de Aragón, Zaragoza (Spain).

\section{CORRESPONDENCE}

* Salvador Ventura and Irantzu Pallarès, Institut de Biotecnologia i Biomedicina and Departament de Bioquímica i Biologia Molecular, Universitat Autònoma de Barcelona, Bellaterra, Barcelona 08193, Spain. Tel: +34 9358689 56; +34 $93 \quad 58147$ 07. E-mail: salvador.ventura@uab.es and irantzu.pallares@uab.cat.

\section{ABBREVIATIONS}

TTR, transthyretin; thyroxine, $\mathrm{T}_{4}$; FAP, familial amyloid polyneuropathy; FAC, familial amyloid cardiomyopathy; ITC, isothermal titration calorimetry; $K_{\mathrm{d}}$, dissociation constant; $\mathrm{nH}$, Hill coefficient; HBP, halogen binding pocket.

\section{DATABASES}

This article has been accepted for publication and undergone full peer review but has not been through the copyediting, typesetting, pagination and proofreading process, which may lead to differences between this version and the Version of Record. Please cite this article as doi: $\underline{10.1111 / \text { febs. } 15339}$

This article is protected by copyright. All rights reserved 
PDB codes for A25T-TTR, V30G-TTR, and Y114C-TTR bound to tolcapone are 6TXV, 6TXW and 6XTK, respectively.

\section{KEYWORDS}

transthyretin; amyloidosis; protein aggregation; crystal structures; tolcapone

\section{ABSTRACT}

Hereditary transthyretin amyloidosis (ATTR) are diseases characterized by the extracellular deposition of transthyretin (TTR) amyloid fibrils. Highly destabilizing TTR mutations cause leptomeningeal amyloidosis, a rare, but fatal, disorder in which TTR aggregates in the brain. The disease remains intractable, since liver transplantation, the reference therapy for systemic ATTR, does not stop mutant TTR production in the brain. In addition, despite current pharmacological strategies have shown to be effective against in vivo TTR aggregation by stabilizing the tetramer native structure and precluding its dissociation, they display low brain permeability. Recently, we have repurposed tolcapone as a molecule to treat systemic ATTR. Crystal structures and biophysical analysis converge to demonstrate that tolcapone binds with high affinity and specificity to three unstable leptomeningeal TTR variants, stabilizing them and, consequently inhibiting their aggregation. Because tolcapone is an FDA-approved drug that crosses the blood-brain-barrier, our results suggest that it can translate into a first disease-modifying therapy for leptomeningeal amyloidosis.

\section{INTRODUCTION}

The misfolding and subsequent aggregation of proteins into amyloid deposits is associated with the onset of a variety of debilitating human disorders, affecting millions of people worldwide [1]. In transthyretin (TTR) amyloidosis, secreted soluble TTR undergoes a conformational change to 
generate toxic extracellular deposits that lead to disease. Plasma circulating TTR is synthesised by the liver. The protein can also be found in the cerebrospinal fluid (CSF) and in the eye, produced by the brain's choroid plexus and the retinal pigment epithelial cells [2, 3], respectively. In the blood, TTR is one of the proteins responsible for the transport and delivery of thyroxine $\left(\mathrm{T}_{4}\right)$ and retinol to cells, whereas, in the CSF, TTR is the primary $\mathrm{T}_{4}$ transporter $[2,4]$.

Amyloidogenesis of wild-type TTR (WT-TTR) is associated with senile systemic amyloidosis, a cardiomyopathy affecting up to $25 \%$ of the population over age 80 [5, 6]. Hereditary transthyretin amyloidosis comprises a life-threatening group of rare monogenic diseases inherited in an autosomal dominant fashion, with most affected individuals being heterozygous for one of the approximately 140 disease-associated TTR mutations [7]. Familial amyloid polyneuropathy (FAP) [8, 9] and the familial amyloid cardiomyopathy (FAC) [10] are the most common forms of hereditary amyloidosis. A reduced number of TTR mutations lead to leptomeningeal amyloidosis, a less well characterized and rare phenotype restricted to the central nervous system (CNS) and defined by preferential amyloid deposition in the leptomeningeal vessels, the brain parenchyma and in the eyes. The predominant CNS symptoms include stroke, recurrent subarachnoid hemorrhage, dementia, ataxia, seizures, depression and periods of decreased consciousness, usually with a poor-prognosis [11, 12].

Human TTR is a $55 \mathrm{kDa}$ homotetrameric protein consisting of four $\beta$-sheet rich subunits of 127 amino acid residues each, usually labelled from $A$ to $D$. The AB/CD dimer-dimer interface creates two identical funnel-shaped $\mathrm{T}_{4}$-binding sites located in opposite sides of the molecule [13, 14]. Scission along this interface is the most probable mechanism of TTR tetramer dissociation, as it is the weakest of the two interfaces in the tetramer [15] and constitutes the rate-limiting step in TTR aggregation. After tetramer dissociation, the dimers readily convert into monomers, which experiment tertiary structural changes to become aggregation competent units [15, 16]. Disease-associated mutations accelerate TTR amyloidosis by thermodynamic or kinetic destabilization of the protein [17, $18]$.

By removing the main source of systemic mutant TTR, liver transplantation has become the reference therapy for hereditary TTR amyloidosis $[19,20]$. However, these patients continue to produce mutant TTR in the choroid plexus and in the eye. Accordingly, CNS TTR deposition has been reported in more than 500 FAP patients after liver transplantation [21, 22].

This article is protected by copyright. All rights reserved 
The pursuit of non-invasive therapies for TTR amyloidosis has fueled the development of small molecules that prevent tetramer dissociation by binding to the two $T_{4}$ pockets, kinetically stabilizing the TTR native state; thus, stalling protein aggregation [23, 24]. Only one of these molecules reached the market for the treatment of TTR amyloidosis, the benzoxazole tafamidis [25].

Tafamidis has been shown to slow down the progression of polyneuropathy [26] and cardiomyopathy [27]. Accordingly, it has been approved in Europe and Japan for the treatment of early-stage FAP [28] and very recently by the Food and Drug Administration (FDA) for the treatment of TTR cardiomyopathy [27]. In contrast, to date, there are no concluding studies on the molecule's ability to halt disease progression in CNS amyloidosis patients. One study suggests that it can attain moderate levels in CSF and the vitreous body [29], whereas others indicate that its blood-brain-barrier (BBB) permeability is too low to reach therapeutic concentrations able to abrogate the aggregation of mutant TTR in the CNS [30, 31].

Using a drug repurposing approach, our group identified tolcapone as a molecule that binds with high affinity and specificity to the two $\mathrm{T}_{4}$-binding sites of TTR, promoting its stabilization and preventing the formation of amyloid fibrils and cytotoxic oligomeric species [32]. Tolcapone is an FDA-approved molecule for Parkinson's disease that has already passed Phase IIa clinical trials for FAP (ClinicalTrials.gov Identifier: NCT02191826) [33, 34]. In this study, tolcapone induced a clear and robust stabilization of plasmatic TTR in all patients studied, the drug was well tolerated, and treatment raised no safety concerns. Of note, tolcapone penetrates the BBB [35] and preliminary data indicated that it might inhibit the aggregation of highly-destabilized variants [32]. Together, these evidences suggested that tolcapone might find therapeutic application in the rare, but fatal, CNS amyloidosis, which, as described, cannot be treated efficiently by liver transplantation or current pharmacological approaches.

In this work, we have characterized in detail the activity of tolcapone on three TTR variants linked to familial leptomeningeal amyloidosis, A25T-TTR [36], V30G-TTR [37] and Y114C-TTR [38], which are among the most destabilized and fastest dissociating TTR tetramers. Our results indicate that tolcapone binds with high affinity to the $\mathrm{T}_{4}$-binding sites of these variants, establishing specific contacts with the tetramer interface that stabilize the mutant proteins and, consequently, 
reduce their aggregation. Overall, these findings converge to demonstrate that tolcapone might become a first broad-spectrum drug to treat TTR-related amyloidosis.

\section{RESULTS AND DISCUSSION}

\section{Tolcapone inhibits the aggregation of TTR leptomeningeal amyloidosis-associated variants}

As a first step to assess if tolcapone can be considered a candidate for treating familial leptomeningeal amyloidosis, we evaluated its ability to prevent the aggregation of the TTR CNS amyloidosis-associated variants A25T-TTR, V30G-TTR and Y114C-TTR (Fig. 1). TTR solutions were incubated in the absence or presence of tolcapone and aggregation was induced by acidification. The molecule final concentration ranged between 0 and $50 \mu \mathrm{M}$. Orthogonal light scattering at $340 \mathrm{~nm}$ was recorded to follow aggregation and normalized to the maximum scattering value in the absence of tolcapone for each individual variant. Interestingly, as shown in Fig. 1, tolcapone inhibits up to $71 \%$ the aggregation of A25T-TTR, 76\% of V30G-TTR and reaches 100\% for Y114C-TTR; the potency for this last mutant being very close to that exerted for WT-TTR. Remarkably, at $5 \mu \mathrm{M}$ of tolcapone, which corresponds to less than 2-fold the protein concentration $(3.5 \mu \mathrm{M})$, the inhibition was already evident for all the TTR variants. Ten molar equivalents of tolcapone $(35 \mu \mathrm{M})$ reduced around $70 \%$ of A25T-TTR aggregation, being equivalent to the anti-aggregational activity of $\mathrm{T}_{4}$ at the same concentration and solution conditions [12].

\section{Tolcapone stabilizes TTR leptomeningeal amyloidosis-associated variants under denaturing conditions}

After demonstrating that tolcapone can inhibit the aggregation of TTR variants linked to familial leptomeningeal amyloidosis, we addressed whether this effect depends on native tetramer stabilization, as previously reported for WT-TTR and the FAC-associated V122I-TTR variant [32].

It is well established that in urea TTR monomer unfolding is preceded by tetramer destabilization [39] and once the tetramer is dissociated, tertiary structural changes can be monitored by tryptophan (Trp) intrinsic fluorescence. Accordingly, to evaluate the effect of tolcapone on the stability of our variants, the proteins were incubated with increasing concentrations of urea (0-9.5 M) for $96 \mathrm{~h}$, allowing the solutions to reach the equilibrium [17, 40], both in the absence and presence of tolcapone $(20$ and $50 \mu \mathrm{M})$. Trp fluorescence was monitored and used to calculate the fraction of

This article is protected by copyright. All rights reserved 
unfolded protein at any given urea concentration (Fig. 2). For A25T-TTR, the obtained curves in both conditions are similar, indicating that, surprisingly, tolcapone does not seem to exert a significant stabilizing effect over this variant in the assayed conditions. In stark contrast, for V30G-TTR and Y114C-TTR a clear stabilizing effect is observed in the presence of tolcapone, being specially dramatic in the case of Y114C-TTR, where tolcapone permits $>50 \%$ of the protein to remain folded at $9.5 \mathrm{M}$ urea, a stabilization that approaches that exerted on WT-TTR.

The low stabilization observed for A25T-TTR might indicate that in this brain aggregating variant, at the assay protein concentration $(1.8 \mu \mathrm{M})$, the tetramer dissociates at such low urea concentrations that the obtained curves report mostly on monomer unfolding. This is consistent with previous findings, indicating that in the $0.72-7.2 \mu \mathrm{M}$ protein concentration range the denaturation curves show a single transition that is concentration independent [18]. This suggests that, at low protein concentrations, A25T-TTR tetramer dissociation and monomer unfolding are not significantly linked. The behavior of A25T-TTR is in stark contrast with that of WT-TTR, for which it is described that tetramer dissociation and monomer unfolding are thermodynamically linked at the protein concentration used in these experiments [18]. Further evidence for these different unfolding mechanisms is provided by the observation that, for A25T-TTR, the urea denaturation curve assessed by resveratrol binding differs significantly from the one monitored by Trp intrinsic fluorescence, whereas for WT-TTR the two curves are nearly coincident (Fig. 3) [12, 18]. Resveratrol has been described to display a substantial increase in its fluorescence quantum yield when bound to at least one of the two $\mathrm{T}_{4}$-binding sites in the tetramer, being thus a reporter for the native state TTR conformation $[17,18]$.

V30G-TTR and Y114C-TTR are clearly more stable and the data herein indicates that they would behave like WT-TTR. Indeed, for these two mutants, the denaturation curves in the presence of tolcapone resemble the ones described for molecules that impose kinetic stability on TTR, stabilizing the $\mathrm{AB} / \mathrm{CD}$ dimer-dimer interface and delaying tetramer dissociation [41, 42].

The analysis emphasizes the complexity of the denaturation mechanism of TTR leptomeningeal-type variants, for which, in contrast to what occurred for WT-TTR and V122I-TTR [32], a direct relationship between tolcapone stabilizing and anti-aggregational effects could not be established. A possible explanation for this lack of correlation would be that the CNS amyloidosis- 
associated variants are so destabilized that, even in the absence of denaturant, only a fraction of the protein remains in a native tetrameric form in the assay conditions. We evaluated the initial tetramer population for each of the TTR mutants under native conditions using resveratrol binding assays (Fig. 4). The proportion of tetramer under native conditions differed among variants, as calculated from resveratrol binding experiments. A25T-TTR, V30G-TTR and Y114C-TTR displayed 43.7 $\pm 3.6 \%$, $59.5 \pm 5.0 \%$ and $96.2 \pm 10.2 \%$ of tetramer relative to that in WT-TTR, respectively. The calculated tetramer populations fairly correlated with the aggregation inhibitory effect that tolcapone exerts in these mutants.

The influence of the mutations on the quaternary structural stability of the different TTR mutants under native conditions was also assessed by analytical size exclusion chromatography (SEC) at $7 \mu \mathrm{M}$ in phosphate buffered saline (PBS) and monitored by absorbance at $280 \mathrm{~nm}$ (Fig. 5). This is the lowest TTR concentration at which our chromatography set up has enough detection sensitivity. V30G-TTR and Y114C-TTR appear as a unique specie with an elution volume corresponding to that of the WT-TTR tetramer. In contrast, in agreement with a lower tetramer stability, A25T-TTR seems to adopt both higher and lower molecular weight species other than the tetramer, likely corresponding to soluble aggregates and a monomer, respectively. This suggests that A25T-TTR dissociates spontaneously at this concentration, generating unfolded monomers that assemble into the majoritarian high-weight species. If this is the case, the equilibrium between the tetrameric and monomeric forms of the mutant protein should be concentration dependent.

Effectively, when analytical SEC was performed at a higher protein concentration $(20 \mu \mathrm{M})$, the elution profile was identical for all the variants, presenting a single peak with an elution volume compatible with the TTR tetramer. This suggests that the amount of initial tolcapone targetable tetramer depends on both the stability of the protein and its concentration in the assay, since both factors impact the equilibrium between the tetrameric and monomeric forms of TTR. It is possible that for highly unstable variants, tolcapone not only would stabilize the available tetramer, but might also displace partially the equilibrium towards the population of the tetrameric form, as a result of Le Chatelier's principle.

\section{Tolcapone binds with high affinity to TTR leptomeningeal amyloidosis-associated variants}

This article is protected by copyright. All rights reserved 
The above described data suggests that tolcapone can inhibit the aggregation of even highly destabilized mutants, as long as they remain in the tetrameric state and the molecule can bind to them. We used isothermal titration calorimetry (ITC) to confirm that tolcapone effectively inter-acts with the brain-associated variants and to determine the mechanisms of binding. The thermodynamic parameters $(\Delta \mathrm{G}, \Delta \mathrm{H},-\mathrm{T} \Delta \mathrm{S})$ for the binding reactions as well as the cooperativity of the interaction were analyzed for the three mutants and WT-TTR according to two models: (1) two identical, but independent binding sites; (2) two identical and cooperative binding sites [43, 44]. Our data indicated that tolcapone binds with high affinity to the first TTR $\mathrm{T}_{4}$-binding site of all proteins, but they exhibit differences in the degree of cooperativity for the binding to the second $\mathrm{T}_{4}$ pocket (Table 1 and Fig. 6).

Importantly, although we first reported that tolcapone binds to WT-TTR with a weak negative cooperativity [32], a reevaluation of the protein-ligand interaction in the present study revealed that under the present assay conditions, the interaction is best described as non-cooperative, with $\mathrm{Kd}=29$ nM. Binding of tafamidis to WT-TTR under the same conditions was assessed as a control and, as expected, a strong negative cooperativity was found, displaying $\mathrm{Kd}_{1}=9.9 \mathrm{nM}$ and $\mathrm{Kd}_{2}=260 \mathrm{nM}$ values, consistent with those previously reported [25]. In agreement with three recent studies [32, 45, 46], these data confirm that the concentration of tolcapone required to occupy simultaneously the two WT-TTR $\mathrm{T}_{4}$ cavities is significantly lower than that of tafamidis in the same conditions, and therefore that tolcapone is a stronger stabilizer of this protein.

The binding of tolcapone to V30G-TTR and Y114C-TTR was also non-cooperative, with Kds for the two binding sites of $110 \mathrm{nM}$ and $45 \mathrm{nM}$, respectively, indicating that tolcapone binds more to the less destabilized Y114C-TTR mutant. Indeed, although the binding of tolcapone to Y114C-TTR is slightly weaker than to WT-TTR, the $\Delta \mathrm{G}$ of the interactions are fairly similar, justifying why, for these initially folded and tetrameric proteins, tolcapone exerts a very similar anti-aggregational effect, being able to abrogate completely TTR deposition at 1:1 $\mathrm{T}_{4}$-binding sites:tolcapone ratio (Fig. 1). In sharp contrast to the other two leptomeningeal variants, the binding of tolcapone to A25T-TTR displays a high negative cooperativity, reflected in a Hill coefficient $(\mathrm{nH})$ of 0.25 . Accordingly, whereas the binding to the first site is strong, with $\mathrm{Kd}_{1}=63 \mathrm{nM}$, the affinity for the second cavity is significantly decreased with a $\mathrm{Kd}_{2}$ in the low $\mu \mathrm{M}$ range $(3.1 \mu \mathrm{M})$.

This article is protected by copyright. All rights reserved 
Irrespectively of the considered TTR mutant and $\mathrm{T}_{4}$ pocket, the binding is always enthalpically driven. This is important because it has been suggested that the enthalpic component of binding plays a predominant role in stabilizing TTR [46] and enthalpic forces correlate with the selectivity of transthyretin binding ligands in plasma [47], explaining why tolcapone binds selectively and stabilizes TTR in the blood of healthy volunteers and patients bearing the polyneuropathy-associated V30M mutation [32, 34]. From our thermodynamic data, the same should be true for the TTR CNS amyloidosis-associated variants in the brain, since the enthalpic component of the binding for these unstable mutants is very similar to the one exhibited for WT-TTR (Fig. 6).

\section{Tolcapone binds TTR leptomeningeal amyloidosis-associated variants at the dimer-dimer interface}

The fact that enthalpic contributions dominate the binding of tolcapone to the three mutant proteins, suggests that, as previously shown for WT-TTR [32], there exist specific interactions between the protein and the ligand. To confirm that these destabilized brain variants could accommodate tolcapone in their tetrameric structure, we obtained crystals of A25T-TTR, V30G-TTR and Y114C-TTR in the presence of tolcapone that diffracted beyond 1.60, 1.15 and $1.69 \AA$ resolution, respectively (Fig. 7 and Table 2 ).

These high-resolution crystal structures clearly indicated the placement of tolcapone in the butterfly-shaped electron density map located in the "weak" dimer-dimer interface of TTR tetramer. As expected, the three new structures were virtually identical to that of WT-TTR in the presence of tolcapone (PDB: 4D7B), with overall root-mean-square deviation values for the C $\alpha$ of $0.20 \AA$ for A25T-TTR (PDB: 6TXV), $0.45 \AA$ for V30G-TTR (PDB: 6TXW) and $0.43 \AA$ for Y114C-TTR (PDB: $6 \mathrm{XTK})$. A closer view into the mutation sites confirms that the mutations do not disturb the structure of TTR and indeed, the local environment around the mutated residues remains unaltered (Fig. 8). This is consistent with the reported data for a vast majority of mutant TTR crystal structures [48]. To the best of our knowledge, the structure of V30G-TTR/tolcapone complex (PDB:6TXW), represents the first one for this protein variant. Val30 maps to the monomer B-strand, our structure indicating that the removal of the side chains of the four buried Val30 residues leads only to minor perturbations of the native tetrameric structure, which are restricted to the vicinity of the mutated residues, e.g. the loss of the intramolecular contacts made with Val71 side-chain in the E-strands. However, the B-

This article is protected by copyright. All rights reserved 
factor of Val71 in V30G-TTR remains similar to the one measured in the WT-TTR/tolcapone complex structure, indicating that the mutation does not even affect local flexibility. The structure of the Y114C-TTR/tolcapone complex is the first one to show that a kinetic stabilizer can diffuse into the $\mathrm{T}_{4}$-binding site of this particular mutant.

In all structures, tolcapone binds to the TTR tetramer in the forward mode, with the 4methyl-phenyl ring occupying the inner binding cavity and the 3,4-dihydroxy-5-nitrophenyl ring of tolcapone oriented to the outer biding cavity. The presence of tolcapone inside of the $\mathrm{T}_{4}$ binding pocket stabilizes the orientation of key residues that form the halogen binding pockets (HBP) HBP11' (Lys15 and Leu17), HBP2-2' (Ala108 and Leu110) and HBP3-3' (Ser117 and Thr119), as inferred from their very well-defined electron maps (Fig. 9). This results in virtually identical polar, hydrophobic contacts and electrostatic interactions inside the $\mathrm{T}_{4}$ pocket to those stabilizing the tetramers in WT-TTR/tolcapone complex structure, including a specific hydrogen bond interaction between the carbonyl group of tolcapone and the hydroxyl side chain of Thr119. The distances between the carbonyl group of tolcapone and the hydroxyl side chain of Thr119 in our structures are similar to the ones observed in the WT-TTR/tolcapone structure and suggest the formation of hydrogen bonds (Table 3). These bonds are buried in the low dielectric context of the $\mathrm{T}_{4}$ pocket, in such a way that these interactions are predicted to be strong (Fig. 7 and Table 3). The establishment of hydrogen bonds between kinetic stabilizers and TTR residues in the inner binding cavity seems to be an important determinant of the binding affinity $[32,46]$.

As in the case of WT-TTR, in the leptomeningeal amyloidosis mutants the $\varepsilon$-amino groups of Lys15/Lys15' are sandwiched between the hydroxyl groups of the phenyl ring of tolcapone and the carboxylate group of Glu54 (Fig. 7 and Table 3). These specific electrostatic interactions by Lys15 close the cavity around tolcapone hampering the entrance of solvent into the pocket and stabilizing the protein-compound complex.

The new structures highlight how the tolcapone-protein interactions at the $\mathrm{T}_{4}$-binding site in the "weak" dimer-dimer interface are not significantly affected by the mutations, providing an explanation for the enthalpy driving binding of the TTR CNS amyloidosis-associated variants and suggesting that the observed anti-aggregational activity of the compound responds to a canonical 
kinetic stabilization of the tetramer once the molecule occupies the hormone-binding sites of the pathogenic proteins.

\section{CONCLUSIONS}

In the present study, we have described in detail the activity of tolcapone, a potent kinetic stabilizer originally intended to treat Parkinson's disease, on TTR variants associated to leptomeningeal amyloidosis, a rare, but fatal form of amyloidosis. We could confirm that A25T-, V30G- and Y114C-TTR variants present lower structural stability compared with WT-TTR, especially A25T-TTR. Mutations impact the tetramer-monomer equilibrium, lowering the ability of these variants to remain in the functional native tetrameric structure, and hence enhancing the protein susceptibility to aggregation. Our study demonstrates that tolcapone binds strongly and canonically at the $\mathrm{T}_{4}$-binding sites of all the assayed TTR leptomeningeal amyloidosis-associated variants, restoring the structural stability of the tetramer and, consequently, inhibiting the pathogenic protein aggregation. This activity, together with the compound's ability to pass the BBB, suggests that tolcapone might become a first broad spectrum pharmacologic treatment for all forms of TTR-related amyloidosis, including the devastating CNS forms of the disease.

All in all, our study provides solid biophysical and structural rational for a recent proof of principle clinical trial aimed to test the ability of tolcapone to stabilize TTR in symptomatic and asymptomatic leptomeningeal TTR patients (ClinicalTrials.gov Identifier: NCT03591757).

\section{MATERIALS AND METHODS}

\section{TTR expression and purification}

The vectors coding for TTR variants were prepared by PCR-site directed mutagenesis using the QuickChange Lightning kit (Agilent technologies, Santa Clara, California, USA). pET28a vector (Novagen, Addgene, Cambridge, USA) encoding for the WT protein was used as a template.

For protein expression, Escherichia coli BL21 (DE3) cells, previously transformed with the corresponding plasmid, were grown in LB medium supplemented with $50 \mu \mathrm{g} \cdot \mathrm{ml}^{-1}$ kanamycin at $37{ }^{\circ} \mathrm{C}$ 
to an optical density of 0.8 at $600 \mathrm{~nm}$, and the culture induced with $1 \mathrm{mM}$ isopropyl $\beta$-Dthiogalactopyranoside for $16 \mathrm{~h}$. Cells were harvested by centrifugation and sonicated, the soluble fraction was recovered by centrifugation. The TTR-containing fraction was obtained by two consecutive steps of ammonium sulphate precipitation (50 and 90\% respectively). The precipitate was solubilized in $25 \mathrm{mM}$ Tris- $\mathrm{HCl}, \mathrm{pH} \mathrm{8}$, and dialysed against the same buffer. The sample was loaded onto a HiTrap Q HP column (GE Healthcare, Illinois, USA) and eluted with a linear gradient $0-0.5$ $\mathrm{M} \mathrm{NaCl}$ in $25 \mathrm{mM}$ Tris- $\mathrm{HCl}, \mathrm{pH}$ 8. The TTR-enriched fractions were precipitated in $90 \%$ ammonium sulphate and the obtained precipitate redissolved in a small volume of buffer $(25 \mathrm{mM}$ Tris, $100 \mathrm{mM}$ $\mathrm{NaCl}, \mathrm{pH} 8$ ). TTR was finally purified by gel filtration chromatography on a HiLoad 26/600 Superdex 75 prep grade column (GE Healthcare) and eluted with $25 \mathrm{mM}$ Tris, $100 \mathrm{mM} \mathrm{NaCl}$. Purest fractions were combined and stored at $-20{ }^{\circ} \mathrm{C}$. Protein concentration was determined spectrophotometrically at $280 \mathrm{~nm}$ using an extinction coefficient of $77600 \mathrm{M}^{-1} \mathrm{~cm}^{-1}$. All the TTR variants, including the WT, were expressed and purified following the same procedure.

\section{TTR aggregation inhibition in vitro}

TTR solutions $(7 \mu \mathrm{M}$ in $10 \mathrm{mM}$ sodium phosphate, $100 \mathrm{mM} \mathrm{KCl,} 1 \mathrm{mM}$ EDTA, $1 \mathrm{mM}$ DTT, $\mathrm{pH}$ 7.0) were incubated with increasing concentrations of tolcapone for $30 \mathrm{~min}$ at $37^{\circ} \mathrm{C}$. Since the stock solutions of tolcapone were prepared in dimethylsulphoxide (DMSO), the percentage of DMSO in all the samples was adjusted to $5 \%(\mathrm{v} / \mathrm{v})$. After the incubation period, the $\mathrm{pH}$ was dropped to 5.0 via dilution 1:1 with acidification buffer $(100 \mathrm{mM}$ sodium acetate, $100 \mathrm{mM} \mathrm{KCl}, 1 \mathrm{mM}$ EDTA, $1 \mathrm{mM}$ DTT, $\mathrm{pH}$ 5.0) and the samples were incubated for more $22 \mathrm{~h}$ at $37^{\circ} \mathrm{C}$. For WT-TTR and Y114C-TTR, a $\mathrm{pH}$ of 4.2 and an incubation period of $72 \mathrm{~h}$ were used instead. The formation of aggregates was assessed by light scattering, with the excitation and emission wavelengths set at $340 \mathrm{~nm}$, using a Varian Cary Eclipse Fluorescence Spectrophotometer (Agilent technologies). TTR aggregation was considered maximum in the absence of tolcapone (100\% aggregation).

\section{Urea denaturation curves in the absence or presence of tolcapone}

Denaturation curves were obtained as described previously [40]. TTR solutions at $1.8 \mu \mathrm{M}$ in PBS were incubated for $30 \mathrm{~min}$ with tolcapone and urea in $50 \mathrm{mM}$ sodium phosphate, $100 \mathrm{mM} \mathrm{KCl}$, $\mathrm{pH} 7.0$, was added to obtain a range of final concentration from 0 to $9.5 \mathrm{M}$. A control sample was 
prepared with DMSO, instead of tolcapone. The concentration of urea in the solutions was verified by refractive index, using a Manual Hand-held Refractometer HR901 (A. Krüss Optronic, Germany). After $96 \mathrm{~h}$ incubation at RT, the fraction unfolded was determined by intrinsic fluorescence spectroscopy, using a FP-8200 Spectrofluorometer (Jasco, Easton, USA). The samples were excited at $295 \mathrm{~nm}$, allowing the selective excitation of the Trp residues on the protein, and fluorescence emission spectra were recorded from 310 to $400 \mathrm{~nm}$. Upon denaturation, the Trp residues become more solvent-exposed and the maximum fluorescence changes from $335 \mathrm{~nm}$ to $355 \mathrm{~nm}$, approximately. The 355/335 $\mathrm{nm}$ fluorescence emission intensity was normalized from minimum (folded) to maximum (unfolded), with the maximum being the sample without tolcapone, and plotted as a function of urea concentration.

\section{Urea mediated transthyretin dissociation measured by resveratrol binding}

A25T- and WT-TTR solutions (1.8 $\mu \mathrm{M}$ in PBS) were incubated with different concentrations of urea buffered with $50 \mathrm{mM}$ sodium phosphate, $100 \mathrm{mM} \mathrm{KCl}, 1 \mathrm{mM}$ EDTA and $1 \mathrm{mM}$ DTT (pH 7.0) for $96 \mathrm{~h}$ at RT. After this time, $1.8 \mu \mathrm{l}$ of resveratrol from a $1 \mathrm{mM}$ stock solution in DMSO was added to a $100 \mu \mathrm{l}$ sample just before the measurement, in order not to shift the equilibrium towards the tetramer [17]. The incubation time with resveratrol was the same for all samples. The samples were excited at $320 \mathrm{~nm}$ and the fluorescence recorded from 350 to $550 \mathrm{~nm}$, using a FP-8200 Spectrofluorometer (Jasco). The fluorescence emission intensity of resveratrol at $394 \mathrm{~nm}$ was used to calculate the amount of non-tetrameric TTR and plotted as a function of urea concentration.

\section{Resveratrol binding to TTR}

In order to assess resveratrol binding to TTR, $1.8 \mu 1$ of resveratrol from a $1 \mathrm{mM}$ stock solution in DMSO were added to $100 \mu \mathrm{TTR}$ samples $(1.8 \mu \mathrm{M}$ in PBS) and the samples were excited at 320 $\mathrm{nm}$, using a FP-8200 Spectro-fluorometer (Jasco). The resveratrol fluorescence intensity at $394 \mathrm{~nm}$ was used as an indicative of the amount of tetrameric TTR present in the samples. The difference between TTR leptomeningeal amyloidosis-associated variants and WT-TTR was analysed by oneway ANOVA Dunnett test using GraphPad Prism 6.0 software (GraphPad Software Inc.). p $<0.05$ was considered statistically significant.

\section{Analytical size exclusion chromatography}


TTR samples (500 $\mu 1$ at $7 \mu \mathrm{M}$ or $100 \mu 1$ at $20 \mu \mathrm{M}$, in PBS) were filtered and injected into a Superdex 75 10/300 GL column (GE Healthcare), previously equilibrated with PBS. Elution was done with the same buffer, at a flow rate of $0.4 \mathrm{ml} / \mathrm{min}$, and monitored by absorbance at $280 \mathrm{~nm}$, which was normalized from 0 to 1 .

\section{Isothermal titration calorimetry}

The thermodynamic parameters that describe the interaction between TTR and tolcapone were determined by ITC, using a MicroCal Auto-iTC200 Calorimeter (MicroCal, Malvern-Panalytical, UK). A25T-, Y114C- and WT-TTR at $5 \mu \mathrm{M}$ located in the calorimetric cell were titrated against tolcapone at $100 \mu \mathrm{M}$ in the injection syringe in PBS buffer $\mathrm{pH}$ 7.0, $100 \mathrm{mM} \mathrm{KCl,} 1 \mathrm{mM}$ EDTA, 2.5\% DMSO, at $25{ }^{\circ} \mathrm{C}$. A stirring speed of $750 \mathrm{rpm}$. and $2 \mu 1$ injections were programmed, with consecutive injections separated by $150 \mathrm{~s}$ to allow the calorimetric signal (thermal power) to return to baseline. For V30G-TTR the concentration of protein was increased to $20 \mu \mathrm{M}$, since the concentration of TTR able to bound tolcapone was low. For each protein, two replicates were performed, and the experimental data was analyzed with a general model for a protein with two ligand-binding sites [43, 44] implemented in Origin 7.0 (OriginLab), which allows to establish whether the two binding sites are identical and independent. Appropriate control blank experiments were performed to test for unwanted heat artefacts or unspecific phenomena.

\section{Crystal structures of TTR/tolcapone complexes}

Co-crystals of A25T-TTR/tolcapone, V30G-TTR/tolcapone and of Y114C-TTR/tolcapone were obtained as described previously [32]. Briefly, purified proteins $(140 \mu \mathrm{M})$ were incubated with tenfold molar excess of ligand for $5 \mathrm{~min}$ at $22^{\circ} \mathrm{C}$. The complex was crystallized at $18{ }^{\circ} \mathrm{C}$ by hangingdrop vapor diffusion by mixing $1 \mu \mathrm{l}$ of the complex with $1 \mu \mathrm{l}$ of the reservoir solution containing 25 and 30\% PEG 400, $200 \mathrm{mM} \mathrm{CaCl}_{2}, 100 \mathrm{mM}$ HEPES, pH 7.0-7.5. Since PEG400 is a cryoprotectant itself, crystals were removed from the drop and directly flash-frozen in liquid nitrogen before diffraction analysis. Diffraction data were recorded from PEG400cryo-cooled crystals (100 K) at the ALBA synchrotron in Barcelona (BL13-XALOC beamline) [49]. Data were integrated and merged using XDS [50] and scaled, reduced and further analyzed using CCP4 [51]. The structure of TTR/tolcapone complex was determined from the X-ray data by molecular replacement with Phenix 
(1.17.1_3660) [52] using the crystal structure of TTR (PDB code 1F41) as a search model. The initial electron density maps showed the well-defined electron density map corresponding to tolcapone in the TTR dimer-dimer interface. Refinement was performed with Phenix [52] and model building was performed with COOT [53]. Ramachandran analysis shows $98.0 \%$ of residues (230) are in preferred regions and only $2.0 \%$ of residues (4) are in allowed regions for the A25T-TTR/tolcapone structure. For the V30G-TTR/tolcapone structure, $98.0 \%$ of residues (235) are in preferred regions and only $2.0 \%$ of residues (4) are in allowed regions. For the Y114C-TTR/tolcapone structure, $96.0 \%$ of residues (227) are in preferred regions and only 4.0\% of residues (10) are in allowed regions. Refinement and data statistics are provided in Table 2. Figures were prepared with PyMOL (DeLano Scientific, LLC).

\section{ACKNOWLEDGMENTS}

This work was funded by the Spanish Ministry of Economy and Competitiveness BIO201678310-R to SV and by ICREA, ICREA-Academia 2015 to SV.

\section{CONFLICT OF INTEREST}

The authors declare no conflict of interest.

\section{AUTHOR CONTRIBUTIONS}

FP, SV and IP designed the study. FP, SE, JS, NV and AVC conducted the experiments. FP, NV, DR, SV and IP analyzed the results. FP, NV, AVC and IP prepared the figures. FP, SV and IP wrote the main manuscript text. All authors reviewed the manuscript.

\section{REFERENCES}

1. Chiti F \& Dobson CM (2017) Protein Misfolding, Amyloid Formation, and Human Disease: A Summary of Progress Over the Last Decade. Annu Rev Biochem 86, 35.1-35.42.

This article is protected by copyright. All rights reserved 
2. Haggen G \& Elliott W (1973) Transport of thyroid hormones in serum and cerebrospinal fluid. $J$ Clin Endocrinol Metab 37, 415-422.

3. Schreiber G, Aldred A, Jaworowski A, Nilsson C, Achen M \& Segal M (1990) Thyroxine transport from blood to brain via transthyretin synthesis in the choroid plexus. Am J Physiol 258, R338-R345.

4. Kanai M, Raz A \& Goodman D (1968) Retinol-binding protein: the transport protein for vitamin A in human plasma. J Clin Invest 47, 2025-2044.

5. Westermark P, Sletten K, Johansson B \& Cornwell GG (1990) Fibril in senile systemic amyloidosis is derived from normal transthyretin. Proc Natl Acad Sci U S A 87 2843-2845.

6. Tanskanen M, Peuralinna T, Polvikoski T, Notkola IL, Sulkava R, Hardy J, Singleton A, KiuruEnari S, Paetau A, Tienari PJ \& Myllykangas L (2008) Senile systemic amyloidosis affects $25 \%$ of the very aged and associates with genetic variation in alpha2-macroglobulin and tau: a populationbased autopsy study. Ann Med 40, 232-239.

7. Rowczenio DM, Noor I, Gillmore JD, Lachmann HJ, Whelan C, Hawkins PN, Obici L, Westermark P, Grateau G \& Wechalekar AD (2014) Online registry for mutations in hereditary amyloidosis including nomenclature recommendations. Hum Mutat 35, E2403-2412.

8. Andrade C (1952) A peculiar form of peripheral neuropathy. Brain 75, 408-427.

9. Saraiva MJ, Birken M, Costa P \& Goodman D (1984) Amyloid fibril protein in familial amyloidotic polyneuropathy, portuguese type definition of molecular abnormality in transthyretin (prealbumin). J Clin Invest 74, 104-119.

10. Jacobson D, Pastore R, Yaghoubian R, Kane I, Gallo G, Buck F \& Buxbaum JN (1997) Variantsequence transthyretin (isoleucin 122) in late-onset cardiac amyloidosis in black americans. $N$ Engl J Med 336, 466-473.

11. Goren H \& Steinberg MC (1980) Familial oculoleptomeningeal amyloidosis. Brain 103, 473-495. 12. Sekijima Y, Hammarström P, Matsumura M, Shimizu Y, Iwata M, Tokuda T, Ikeda S-i \& Kelly JW (2003) Energetic Characteristics of the New Transthyretin Variant A25T May Explain Its Atypical Central Nervous System Pathology. Laboratory Investigation 83, 409-417.

13. Blake CCF, Geisow MJ, Swan IDA, Rerat C \& Rerat B (1974) Structure of human plasma prealbumin at $2.5 \mathrm{~A}$ resolution. A preliminary report on the polypeptide chain conformation, quaternary structure and thyroxine binding. J Mol Biol 88, 1-12.

This article is protected by copyright. All rights reserved 
14. Blake CCF, Geisow MJ, Oatley SJ, Rérat B \& Rérat C (1978) Structure of prealbumin: secondary, tertiary and quaternary interactions determined by Fourier refinement at 1.8 A. J Mol Biol 121, 339356.

15. Foss TR, Wiseman RL \& Kelly JW (2005) The pathway by which the tetrameric protein transthyretin dissociates. Biochemistry 44, 15525-15533.

16. Zhihong L, Wilfredo C \& Kelly JW (1996) The acid-mediated denaturation pathway of transthyretin yields a conformational intermediate that can self-assemble into amyloid. Biochemistry 35, 6470-6482.

17. Hammarstrom P, Jiang X, Hurshman AR, Powers ET \& Kelly JW (2002) Sequence-dependent denaturation energetics: A major determinant in amyloid disease diversity. Proc Natl Acad Sci U S A 99 Suppl 4, 16427-16432.

18. Hurshman Babbes AR, Powers ET \& Kelly JW (2008) Quantification of the thermodynamically linked quaternary and tertiary structural stabilities of transthyretin and its disease-associated variants: the relationship between stability and amyloidosis. Biochemistry 47, 6969-6984.

19. Holmgren G, Steen L, Ekstedt J, Groth CG, Ericzon BG, Eriksson S, Andersen O, Karlberg I, Nordén G, Nakazato M, Hawkins PN, Richardson S \& Pepys MB (1991) Biochemical effect of liver transplantation in two Swedish patients with familial amyloidotic polyneuropathy (FAP-met ${ }^{30}$ ). Clin Genet 40, 242-246.

20. Rapezzi C, Quarta CC, Riva L, Longhi S, Gallelli I, Lorenzini M, Ciliberti P, Biagini E, Salvi F \& Branzi A (2010) Transthyretin-related amyloidoses and the heart: a clinical overview. Nat Rev Cardiol 7, 398-408.

21. Maia LF, Magalhaes R, Freitas J, Taipa R, Pires MM, Osorio H, Dias D, Pessegueiro H, Correia $\mathrm{M}$ \& Coelho $\mathrm{T}$ (2015) CNS involvement in V30M transthyretin amyloidosis: clinical, neuropathological and biochemical findings. J Neurol Neurosurg Psychiatry 86, 159-167.

22. Sakashita N, Ando Y, Jinnouchi K, Yoshimatsu M, Terazaki H, Obayashi K \& Takeya M (2001) Familial amyloidotic polyneuropathy (ATTR Val30Met) with widespread cerebral amyloid angiopathy and lethal cerebral hemorrhage. Pathol 51, 475-480.

This article is protected by copyright. All rights reserved 
23. Johnson SM, Wiseman RL, Sekijima Y, Green NS, Adamski-Werner SL \& Kelly JW (2005) Native state kinetic stabilization as a strategy to ameliorate protein misfolding diseases: a focus on the transthyretin amyloidoses. Acc Chem Res 38, 911-21.

24. Hammarstrom P (2003) Prevention of transthyretin amyloid disease by changing protein misfolding energetics. Science 299, 713-716.

25. Bulawa CE, Connelly S, Devit M, Wang L, Weigel C, Fleming JA, Packman J, Powers ET, Wiseman RL, Foss TR, Wilson IA, Kelly JW \& Labaudiniere R (2012) Tafamidis, a potent and selective transthyretin kinetic stabilizer that inhibits the amyloid cascade. Proc Natl Acad Sci U S A 109, 9629-9634.

26. Coelho T, Maia LF, da Silva AM, Cruz MW, Plante-Bordeneuve V, Suhr OB, Conceicao I, Schmidt HH, Trigo P, Kelly JW, Labaudiniere R, Chan J, Packman J \& Grogan DR (2013) Long-term effects of tafamidis for the treatment of transthyretin familial amyloid polyneuropathy. J Neurol $\mathbf{2 6 0}$, 2802-2814.

27. Maurer MS, Schwartz JH, Gundapaneni B, Elliott PM, Merlini G, Waddington-Cruz M, Kristen AV, Grogan M, Witteles R, Damy T, Drachman BM, Shah SJ, Hanna M, Judge DP, Barsdorf AI, Huber P, Patterson TA, Riley S, Schumacher J, Stewart M, Sultan MB \& Rapezzi C (2018) Tafamidis Treatment for Patients with Transthyretin Amyloid Cardiomyopathy. N Engl J Med 379, 1007-1016. 28. Coelho T, Maia LF, da Silva AM, Cruz MW, Plante-Bordeneuve V, Lozeron P, Suhr OB, Campistol JM, Conceicao I, Schmidt H, Trigo P, Kelly JW, Labaudiniere R, Chan J, Packman J, Wilson A \& Grogan DR (2012) Tafamidis for familial amyloid polyneuropathy. A randomized, controlled trial. Neurology 79, 785-792.

29. Monteiro C, Martins da Silva A, Ferreira N, Mesgarzadeh J, Novais M, Coelho T \& Kelly JW (2018) Cerebrospinal fluid and vitreous body exposure to orally administered tafamidis in hereditary ATTRV30M (p.TTRV50M) amyloidosis patients. Amyloid 25, 120-128.

30. Casal I, Monteiro S \& Beirao JM (2016) Tafamidis in hereditary ATTR amyloidosis - our experience on monitoring the ocular manifestations. Amyloid 23, 262-263.

31. Salvi F, Volpe R, Pastorelli F, Bianchi A, Vella A, Rapezzi C \& Mascalchi M (2018) Failure of Tafamidis to Halt Progression of Ala36Pro TTR Oculomeningovascular Amyloidosis. J Stroke Cerebrovasc Dis 27, e212-e214.

This article is protected by copyright. All rights reserved 
32. Sant'Anna R, Gallego P, Robinson LZ, Pereira-Henriques A, Ferreira N, Pinheiro F, Esperante S, Pallares I, Huertas O, Almeida MR, Reixach N, Insa R, Velazquez-Campoy A, Reverter D, Reig N \& Ventura S (2016) Repositioning tolcapone as a potent inhibitor of transthyretin amyloidogenesis and associated cellular toxicity. Nat Commun 7, 10787.

33. Gomes J, Salvadó M, Reig N, Suñé P, Casanovas C, Rojas-Garcia R \& Insa R (2019) Transthyretin stabilization activity of the catechol- $O$-methyltransferase inhibitor tolcapone (SOM0226) in hereditary ATTR amyloidosis patients and asymptomatic carriers: proof-of-concept study. Amyloid 26, 74-84.

34. Reig N, Ventura S, Salvadó M, Gámez J \& Insa R (2015) SOM0226, a repositioned compound for the treatment of TTR amyloidosis. Orphanet J Rare Dis 10, P9.

35. Russ H, Müller T, Woitalla D, Rahbar A, Hahn J \& Kuhn W (1999) Detection of tolcapone in the cerebrospinal fluid of parkinsonian subjects. Naunyn-Schmiedeberg's Arch Pharmacol 360, 719-720.

36. Hagiwara K, Ochi H, Suzuki S, Shimizu Y, Tokuda T, Murai H, Shigeto H, Ohyagi Y, Iwata M, Iwaki T \& Kira J (2009) Highly selective leptomeningeal amyloiosis with transthyretin variant ala25thr. Neurology 72, 1358-1359.

37. Petersen RB, Goren H, Cohen M, Richardson SL \& Tresser N (1997) Transthyretin amyloidosis: a new mutation associated with dementia. Ann Neurol 41, 307-313.

38. Ueno S, Uemichi T, Yorifuji S \& Tarui S (1990) A novel variant of transthyretin (Tyr114 to Cys) deduced from nucleotide sequences of gene fragments from familial amyloidotic polyneuropathy in japanese sibiling cases. Biochem Biophys Res Commun 169, 143-147.

39. Hammarstrom P, Jiang X, Deechongkit S \& Kelly JW (2001) Anion shielding of electrostatic repulsions in transthyretin modulates stability and amyoidosis: insight into the chaotrope unfolding dichotomy. Biochemistry 40, 11453-11459.

40. Sant'Anna R, Almeida MR, Varejao N, Gallego P, Esperante S, Ferreira P, Pereira-Henriques A, Palhano FL, de Carvalho M, Foguel D, Reverter D, Saraiva MJ \& Ventura S (2017) Cavity filling mutations at the thyroxine-binding site dramatically increase transthyretin stability and prevent its aggregation. Sci Rep 7, 44709.

This article is protected by copyright. All rights reserved 
41. McCammon MG, Scott DJ, Keetch CA, Greene LH, Purkey H, Petrassi HM, Kelly JW \& Robinson CV (2002) Screening transthyretin amyloid fibril inhibitors: characterization of novel multiprotein, multiligand complexes by mass spectrometry. Structure 10, 851-863.

42. Pullakhandam R, Srinivas PN, Nair MK \& Reddy GB (2009) Binding and stabilization of transthyretin by curcumin. Arch Biochem Biophys 485, 115-119.

43. Vegan S, Abian O \& Velazquez-Campoy A (2015) A unified framework based on the binding polynomial for characterizing biological systems by isothermal titration calorimetry. Methods 76, 99115.

44. Freire E, Schön A \& Velazquez-Campoy A (2009) Chapter 5 Isothermal titration calorimetry. General formalism using binding polynomials. Methods Enzymol 455, 127-155.

45. Verona G, Mangione PP, Raimondi S, Giorgetti S, Faravelli G, Porcari R, Corazza A, Gillmore JD, Hawkins PN, Pepys MB, Taylor GW \& Bellotti V (2017) Inhibition of the mechano-enzymatic amyloidogenesis of transthyretin: role of ligand affinity, binding cooperativity and occupancy of the inner channel. Sci Rep 7, 182.

46. Miller M, Pal A, Albusairi W, Joo H, Pappas B, Haque Tuhin MT, Liang D, Jampala R, Liu F, Khan J, Faaij M, Park M, Chan W, Graef I, Zamboni R, Kumar N, Fox J, Sinha U \& Alhamadsheh M (2018) Enthalpy-Driven Stabilization of Transthyretin by AG10 Mimics a Naturally Occurring Genetic Variant That Protects from Transthyretin Amyloidosis. J Med Chem 61, 7862-7876.

47. Iakovleva I, Brännström K, Nilsson L, Gharibyan A, Begum A, Anan I, Walfridsson M, SauerEriksson AE \& Olofsson A (2015) Enthalpic forces correlate with the selective of transthyretinstabilizing ligands in human plasma. J Med Chem 58, 6507-6515.

48. Palaninathan SK (2012) Nearly 200 X-ray crystal structures of transthyretin: what do they tell us about this protein and the design of drugs for TTR amyloidoses? Curr Med Chem 19, 2324-2342.

49. Juanhuix J, Gil-Ortiz F, Cuni G, Colldelram C, Nicolas J, Lidon J, Boter E, Ruget C, Ferrer S \& Benach J (2014) Developments in optics and performance at BL13-XALOC, the macromolecular crystallography beamline at the ALBA synchrotron. J Synchrotron Radiat 21, 679-689.

50. Kabsch W (2010) Integration, scaling, space-group assignment and post-refinement. Acta Crystallogr D Biol Crystallogr 66, 133-144.

This article is protected by copyright. All rights reserved 
51. Winn MD, Ballard CC, Cowtan KD, Dodson EJ, Emsley P, Evans PR, Keegan RM, Krissinel EB, Leslie AG, McCoy A, McNicholas SJ, Murshudov GN, Pannu NS, Potterton EA, Powell HR, Read RJ, Vagin A \& Wilson KS (2011) Overview of the CCP4 suite and current developments. Acta Crystallogr D Biol Crystallogr 67, 235-242.

52. Adams PD, Afonine PV, Bunkoczi G, Chen VB, Davis IW, Echols N, Headd JJ, Hung LW, Kapral GJ, Grosse-Kunstleve RW, McCoy AJ, Moriarty NW, Oeffner R, Read RJ, Richardson DC, Richardson JS, Terwilliger TC \& Zwart PH (2010) PHENIX: a comprehensive Python-based system for macromolecular structure solution. Acta Crystallogr D Biol Crystallogr 66, 213-221.

53. Emsley P, Lohkamp B, Scott WG \& Cowtan K (2010) Features and development of Coot. Acta Crystallogr D Biol Crystallogr 66, 486-501.

\section{FIGURE LEGENDS}

Fig. 1. Tolcapone effect over the aggregation of TTR leptomeningeal amyloidosis-associated variants. (A) A25T-TTR (in red), (B) V30G-TTR (in blue), (C) Y114C-TTR (in green) and WT-TTR (in black). Light scattering at $340 \mathrm{~nm}$ was measured and plotted as percentage of TTR aggregation. The values represent mean \pm s.e.m $(n=3)$.

Fig. 2. Tolcapone effect on urea-induced denaturation of TTR leptomeningeal amyloidosis-associated variants. (A) A25T-TTR, (B) V30G-TTR, (C) Y114C-TTR and (D) WT-TTR. Black squares represent the control without tolcapone, while gold and magenta squares correspond to the samples incubated with 20 and $50 \mu \mathrm{M}$ of tolcapone, respectively. The values represent mean \pm s.e.m $(\mathrm{n}=3)$.

Fig. 3. Urea denaturation of the leptomeningeal-associated TTR variant A25T-TTR and WT-TTR. Stability of A25T-TTR (in red) and WT-TTR (in black) was assessed both by resveratrol binding (filled circles, left axis) and Trp intrinsic fluorescence (open circles, right axis). Raw resveratrol binding and Trp intrinsic fluorescence data is shown in (A) and (B). These values were used to calculate the non-tetrameric fraction and unfolded fraction, respectively, which are presented in $(\mathrm{C})$ and (D).

This article is protected by copyright. All rights reserved 
Fig. 4. Resveratrol binding of TTR leptomeningeal amyloidosis-associated variants. Resveratrol fluorescence at $394 \mathrm{~nm}$ when incubated with A25T-TTR (in red), V30G-TTR (in blue), Y114C-TTR (in green) and WT-TTR (in black). The values represent mean \pm s.e.m $(n=3)$. One-way ANOVA Dunnett test revealed differences between A25T- and V30G-TTR binding to resveratrol, in comparison to WT-TTR; *p $<0.05$ and $* * \mathrm{p}<0.01$.

Fig. 5. Effect of protein concentration on the quaternary structure adopted by TTR leptomeningeal amyloidosis-associated variants. (A-D) Elution profiles of A25T-TTR (in red), V30G-TTR (in blue), Y114C-TTR (in green) and WT-TTR (in black) at 7 (solid line) or $20 \mu \mathrm{M}$ (dashed line).

Fig. 6. Calorimetric titration of TTR leptomeningeal amyloidosis-associated variants with tolcapone. (A) The top panel (thermogram) shows how the thermal power changes with time. The bottom panel (binding isotherm) is obtained from the transformation of the thermogram and represents the normalized heat of reaction per injection as a function of the ratio between the molar concentration of tolcapone and protein. The solid line in the binding isotherm corresponds to the best fitting to each curve. (B) Graphical representation of $\Delta \mathrm{G}$ (dark bars), $\Delta \mathrm{H}$ (light bars) and -T $\Delta \mathrm{S}$ (striped bars) for the binding of tolcapone to the first and second site of A25T-TTR (in red), V30G-TTR (in blue), Y114CTTR (in green) and WT-TTR (in black). In the case of V30G-, Y114C- and WT-TTR, the binding parameters for both sites are the same.

Fig. 7. Crystal structures of A25T-TTR, V30G-TTR and Y114C-TTR in complex with tolcapone. (A) Global view of TTR variants bound to tolcapone (cartoon representation). The electron density maps of the two tolcapone-binding sites of tolcapone are depicted. The position of the mutated residues in the structure is specified with asterisks. Dashed lines represent the two-fold symmetry axis of the dimer-dimer interface. (B) Detailed and close-up views of one of the TTR tolcapone-binding sites of the variants (PDB: 6TXV, 6TXW, 6XTK); tolcapone and some of the TTR tetramer residues in contact with it are represented by sticks. (C) Close-up views of the electron density map of the mutated residues. All structures were generated with PyMOL (DeLano Scientific, LLC).

Fig. 8. Comparison between the crystal structures of WT-TTR with A25T-TTR, V30G-TTR and Y114C-TTR in complex with tolcapone. Superposition of WT-TTR (light blue) and A25T (green), 
V30G (raspberry) and Y114C (olive) variant structures. (Right) Superposed tetramers are depicted in cartoon representation and tolcapone molecules are showed in stick. (Left) Close up view showing the local environment of the mutated residues in monomer A (stick representation), Thr25, Gly30 and Cys 114 are colored by elements. The overall root-mean-square deviation for the superposed $\mathrm{C} \alpha$ atoms are $0.20 \AA, 0.45 \AA$ and $0.43 \AA$, respectively. All structures were generated with PyMOL (DeLano Scientific, LLC).

Fig. 9. Stereo images of TTR leptomeningeal amyloidosis-associated variants and electron density maps of tolcapone and of residues involved in binding. Stereo views of (A) A25T-TTR, (B) V30GTTR and (C) Y114C-TTR in complex with tolcapone with a 2Fo-Fcmap (blue mesh) contoured at 1.0 $\sigma$. All structures were generated with PyMOL (DeLano Scientific, LLC).

\section{TABLES}

Table 1. Thermodynamic parameters obtained by ITC experiments for the binding of tolcapone to TTR leptomeningeal amyloidosis-associated variants*.

\begin{tabular}{|c|c|c|c|c|c|c|c|c|c|}
\hline & $\begin{array}{c}\mathrm{Kd}_{1} \\
(\mu \mathrm{M})\end{array}$ & $\begin{array}{c}\Delta \mathbf{G}_{1} \\
(\mathrm{kcal} / \mathrm{mol})\end{array}$ & $\begin{array}{c}\Delta \mathbf{H}_{1} \\
(\mathrm{kcal} / \mathrm{mol})\end{array}$ & $\begin{array}{c}-\mathrm{T} \Delta \mathrm{S}_{1} \\
(\mathrm{kcal} / \mathrm{mol})\end{array}$ & $\begin{array}{c}\mathbf{K d}_{2} \\
(\mu \mathrm{M})\end{array}$ & $\begin{array}{c}\Delta \mathbf{G}_{2} \\
(\mathrm{kcal} / \mathrm{mol})\end{array}$ & $\begin{array}{c}\mathbf{H}_{2} \\
(\mathrm{kcal} / \mathrm{mol})\end{array}$ & $\begin{array}{c}-\mathrm{T} \Delta \mathrm{S}_{2} \\
(\mathrm{kcal} / \mathrm{mol})\end{array}$ & $\mathbf{n H}$ \\
\hline A25T & 0.063 & -9.8 & -17.1 & 7.3 & 3.1 & -7.5 & -12.3 & 4.8 & 0.25 \\
\hline V30G & 0.110 & -9.5 & -12.3 & 2.8 & 0.110 & -9.5 & -12.3 & 2.8 & 1 \\
\hline Y114C & 0.045 & -10.0 & -14.4 & 4.4 & 0.045 & -10.0 & -14.4 & 4.4 & 1 \\
\hline WT & 0.029 & -10.3 & -8.8 & -1.5 & 0.029 & -10.3 & -8.8 & -1.5 & 1 \\
\hline
\end{tabular}

* 1 and 2 correspond to the parameters associated with the first and second binding site of TTR, respectively.

This article is protected by copyright. All rights reserved 
Table 2. Data collection and refinement statistics of transthyretin variants in complex with tolcapone*.

\begin{tabular}{|c|c|c|c|}
\hline & A25T-TTR & V30G-TTR & Y114C-TTR \\
\hline \multicolumn{4}{|l|}{ Data collection } \\
\hline Space group & $P 2_{1} 22_{1}$ & $P 2_{1} 22_{1}$ & $P 2_{1} 22_{1}$ \\
\hline Unit cell parameters $(\AA)$ & $43.83,65.41,84.67$ & $43.67,65.63,84.35$ & $42.92,65.74,83.95$ \\
\hline Wavelength (nm) & 0.9794 & 0.9790 & 0.9795 \\
\hline Resolution range $(\AA)$ & $42.34-1.55$ & $65.63-1.15$ & $65.74-1.69$ \\
\hline $\mathrm{R}_{\text {merge }}$ & $0.04(0.47)$ & $0.12(0.96)$ & $0.05(0.90)$ \\
\hline $\mathrm{CC}_{1 / 2}$ & $0.99(0.92)$ & $0.98(0.63)$ & $0.99(0.63)$ \\
\hline $\mathrm{I} / \sigma_{\mathrm{I}}$ & $23.5(3.8)$ & $8.1(1.5)$ & $8.0(0.9)$ \\
\hline Completeness (\%) & $99.5(98.2)$ & $96.5(95.3)$ & $99.4(97.0)$ \\
\hline Multiplicity & $5.4(5.0)$ & $6.3(5.1)$ & $3.4(3.2)$ \\
\hline \multicolumn{4}{|l|}{ Structure refinement } \\
\hline Resolution range $(\AA)$ & $42.33-1.60$ & $65.63-1.15$ & $38.22-1.70$ \\
\hline No. of unique reflections & 32836 & 82985 & 26585 \\
\hline $\mathrm{R}_{\text {work }} / \mathrm{R}_{\text {free }}(\%)$ & $19.0 / 21.5$ & $15.9 / 18.5$ & $19.2 / 22.0$ \\
\hline No. of atoms & 2070 & 2165 & 1905 \\
\hline Protein & 1854 & 1854 & 1764 \\
\hline Ligands & 40 & 40 & 40 \\
\hline Water molecules & 188 & 279 & 105 \\
\hline Average $\mathrm{B}$ factors $\left(\AA^{2}\right)$ & 26.1 & 25.7 & 42.6 \\
\hline Protein & 25.3 & 23.8 & 42.4 \\
\hline Ligands & 25.1 & 21.7 & 44.5 \\
\hline Water & 34.5 & 39.5 & 45.2 \\
\hline \multicolumn{4}{|l|}{ RMS deviations } \\
\hline Bonds $(\AA)$ & 0.003 & 0.007 & 0.009 \\
\hline Angles $\left({ }^{\circ}\right)$ & 0.60 & 0.89 & 0.96 \\
\hline PDB code & 6TXV & 6TXW & 6XTK \\
\hline
\end{tabular}

*Values in parenthesis are for the last resolution shell.

Table 3. Comparison of the interatomic distances (in $\AA$ ) between the two tolcapone molecules of the tetramer and residues of WT-TTR and TTR variants that form HBP1 and -1' and HBP2 and 2 ' binding sites*.

\begin{tabular}{lcccc} 
& WT-TTR & A25T-TTR & V30G-TTR & Y114C-TTR \\
\hline Thr119 OG1 - tolcapone O13 & $2.6(2.5)$ & $2.6(2.6)$ & $2.5(2.5)$ & $3.0(3.0)$ \\
Lys15 NZ - tolcapone O8 & $2.7(2.9)$ & $2.8(2.8)$ & $3.1(2.7)$ & $2.9(2.6)$ \\
Lys15 NZ - Glu54 OE2 & $2.8(2.9)$ & $3.2(3.3)$ & $3.1(3.4)$ & $2.9(3.9)$ \\
\hline
\end{tabular}

* Values in parenthesis correspond to the second tolcapone molecule.

This article is protected by copyright. All rights reserved 

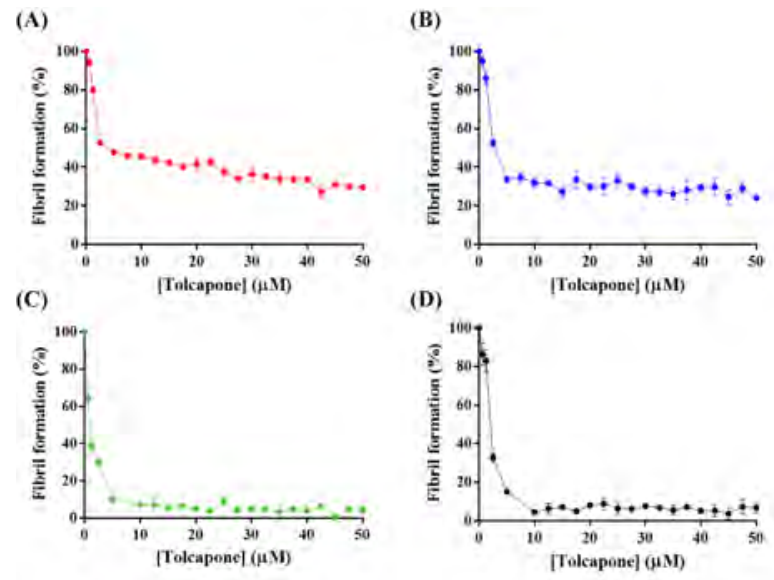

febs_15339_f1.tiff 

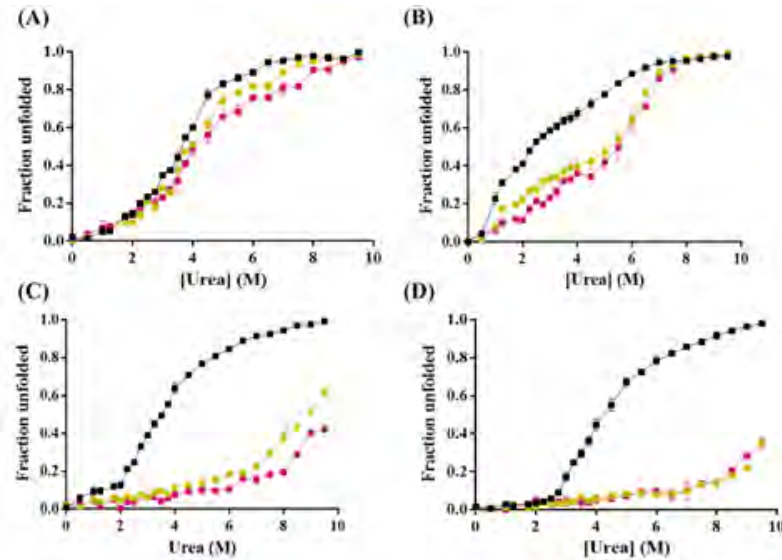

febs_15339_f2.tiff

This article is protected by copyright. All rights reserved 

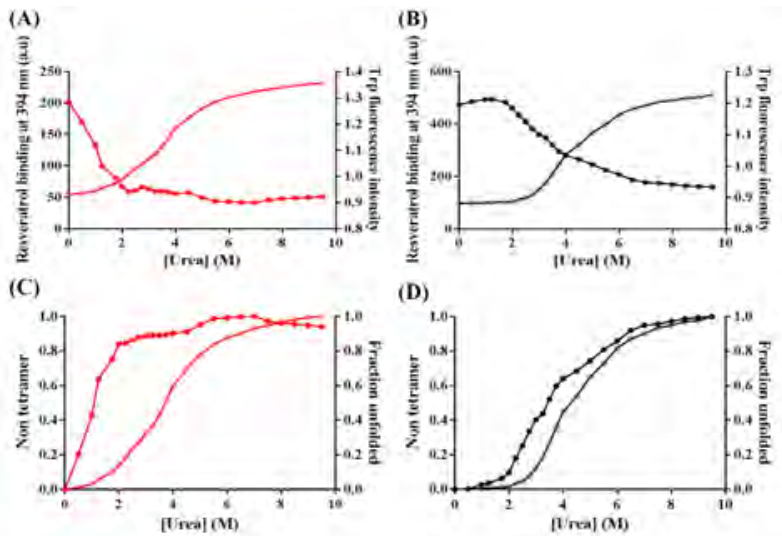

(D)

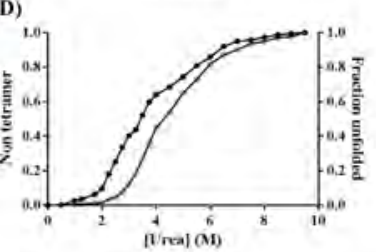

febs_15339_f3.tif

This article is protected by copyright. All rights reserved 


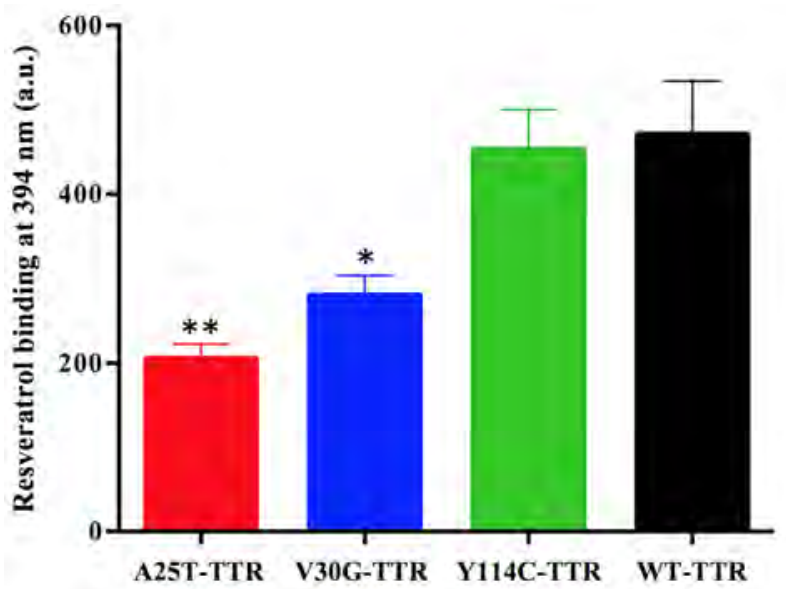

febs_15339_f4.tif 

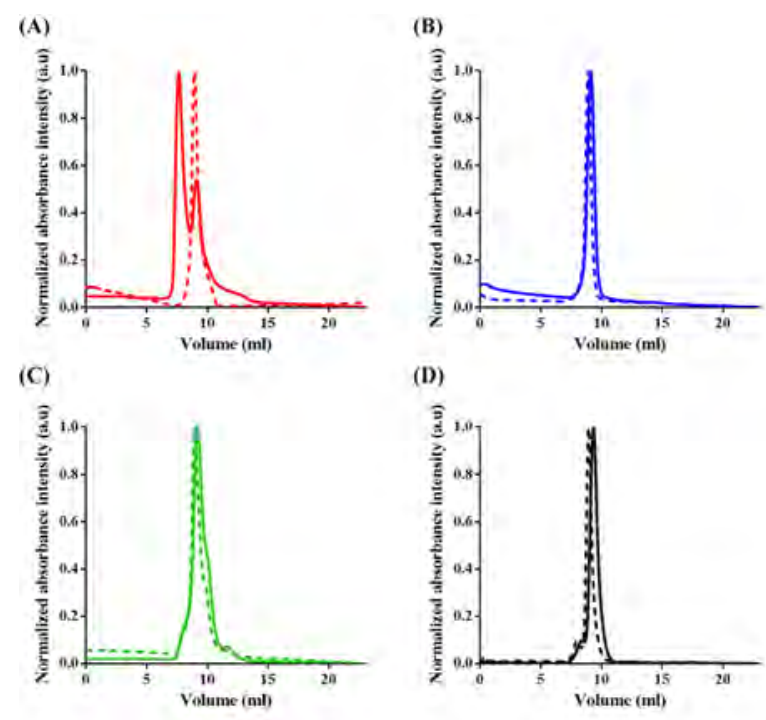

febs_15339_f5.tif 

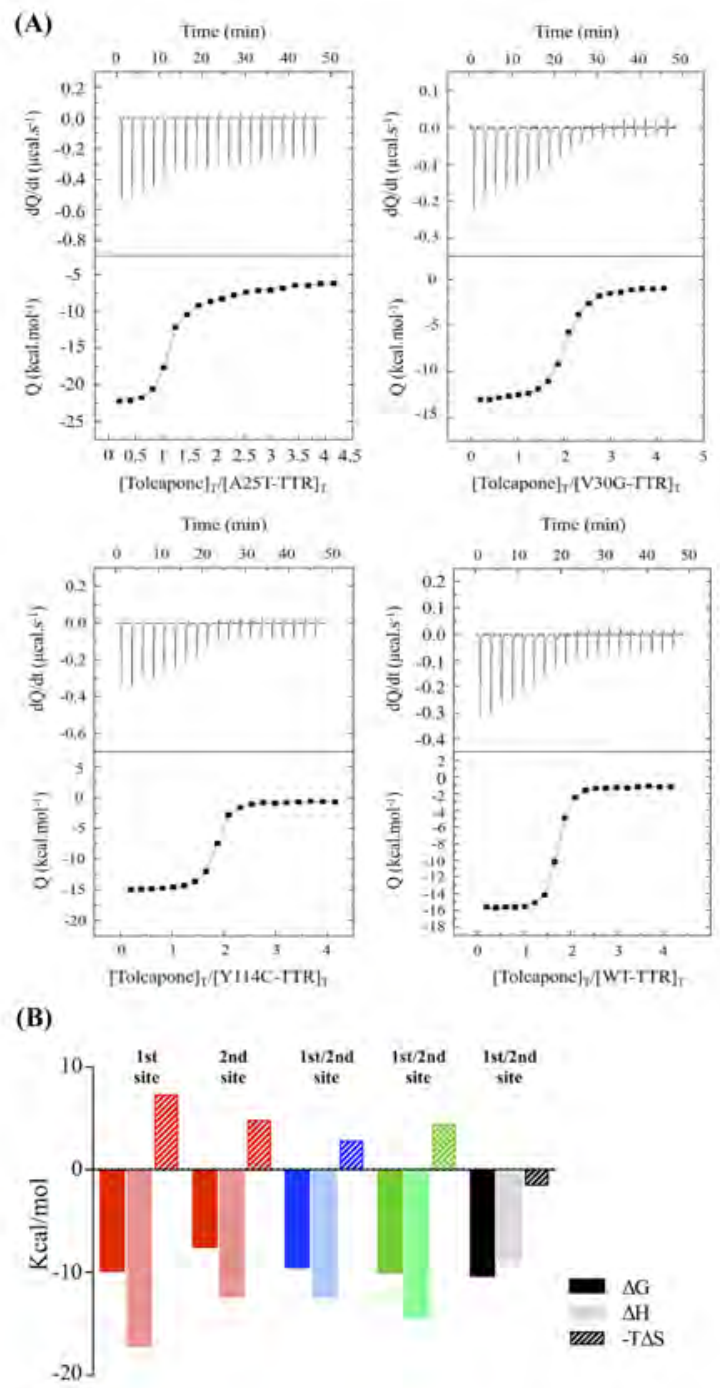

febs_15339_f6.tif 
(A)
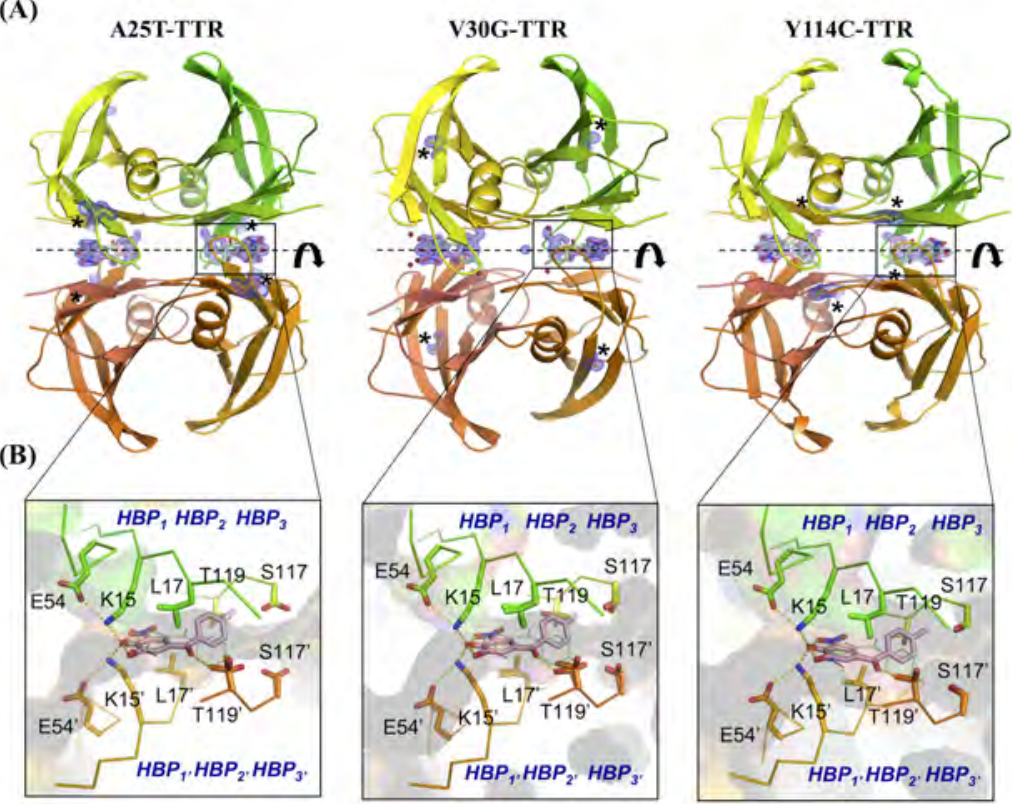

(C)
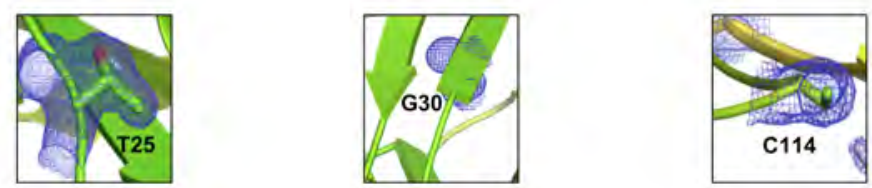

febs_15339_f7.tif 

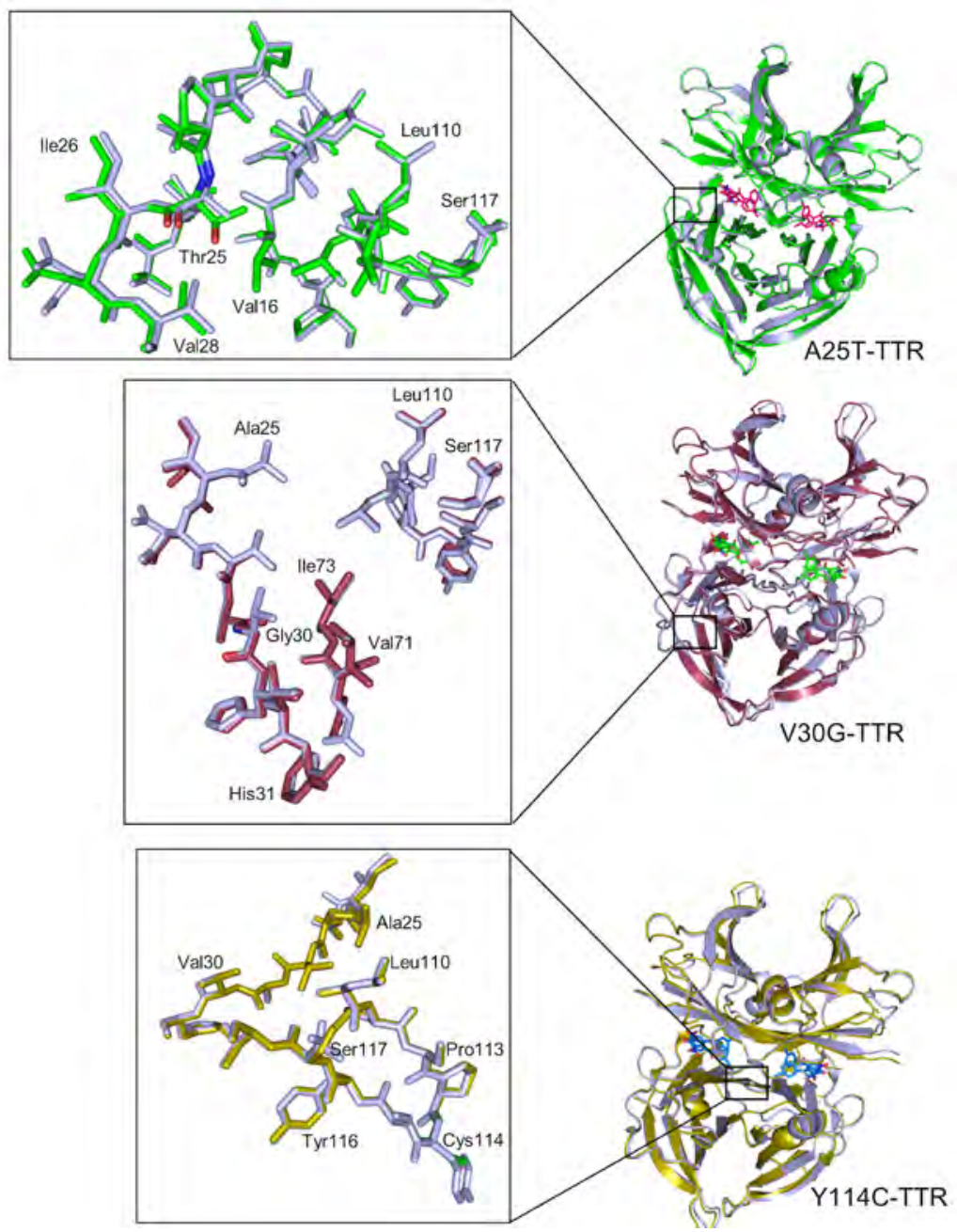

febs_15339_f8.tif

This article is protected by copyright. All rights reserved 
(A)

A25T-TTR

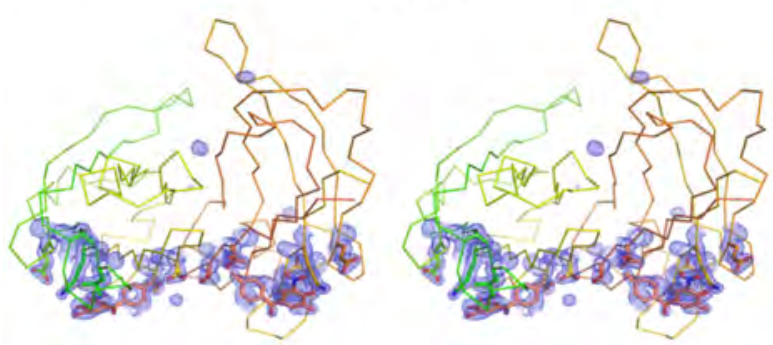

(B)

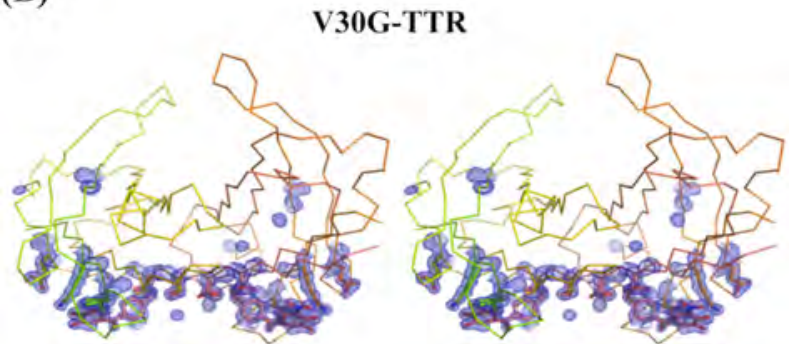

(C)

Y114C-TTR

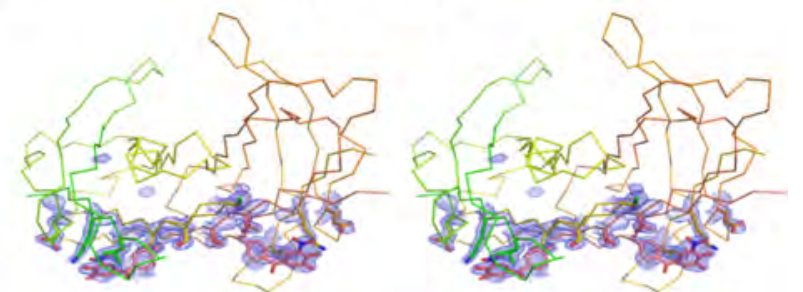

febs_15339_f9.tif

This article is protected by copyright. All rights reserved 